\title{
Pengatur Intensitas Cahaya Ruangan dengan Fuzzy Logic Menggunakan PLC
}

Arif Budi Setiawan', Riky Dwi Puriyanto

${ }^{1}$ Mahasiswa Program Studi Teknik Elektro, Universitas Ahmad Dahlan, Indonesia

${ }^{2}$ Dosen Program Studi Teknik Elektro, Universitas Ahmad Dahlan, Indonesia

\section{INFORMASI ARTIKEL}

\section{Riwayat Artikel:}

Dikirimkan 02 September 2019,

Direvisi 02 Oktober 2019,

Diterima 10 Oktober 2019.

\section{Kata Kunci:}

Intensitas Cahaya,

Fuzzy Logic,

Kendali Cahaya,

PLC,

Sensor LDR.

\section{Penulis Korespondensi:}

Riky Dwi Puriyanto,

Program Studi Teknik Elektro

Universitas Ahmad Dahlan,

Yogyakarta, Indonesia.

Surel: rikydp@ee.uad.ac.id

\begin{abstract}
ABSTRAK
Sistem penerangan ruangan konvensional kurang efisien dalam penggunaan energi karena hanya menggunakan prinsip menyalakan (on) dan mematikan (off) lampu serta tidak menghiraukan pengaruh dan kontribusi dari luar atau pencahayaan matahari. Untuk mengatasi permasalahan tersebut dibuatlah sistem pengendalian cahaya lampu penerangan secara otomatis menggunakan Programmable Logic Controller (PLC) Omron sebagai pengendali. Proses pengendalian intensitas cahaya lampu, pada ruangan memanfaatkan dua sensor cahaya berjenis Light Dependent Resistance (LDR) dengan menggunakan metode fuzzy Sugeno sebagai cara pengambilan keputusan dengan dua himpunan dan tiga variabel disetiap himpunan, sedangkan untuk mengubah kembali ke bentuk bilangan crisp atau defuzzyfikasi menggunakan metode Centroid. Kendali fuzzy logic sangat tepat digunakan untuk pengendalian sistem yang bersifat nonlinear dan adaptif. Berdasarkan hasil pengujian, sistem yang dibangun dapat berjalan dengan baik dengan tingkat akurasi pengendalian sebesar 99,38\% yang diperoleh dari perbandingan antara pengujian sistem langsung dan pengujian dengan Matlab.

Conventional room lighting systems are less efficient in energy use because they only use the principle of turning on (off) and turning off (off) lights and ignoring the influence and contribution of outside or solar lighting. To overcome these problems, a lighting control system was made automatically using the Omron Programmable Logic Controller (PLC) as a controller. The process of controlling light intensity, in a room utilizing two light sensors, type Light Dependent Resistance (LDR) using the Sugeno fuzzy method as a way of making decisions with two sets and three variables in each set, while to change back to the form of crisp numbers or defuzzification using the Centroid method. Fuzzy logic control is very appropriate to be used for controlling systems that are non-linear and adaptive. Based on the test results, the system built can run well with a level of accuracy of control of $99.38 \%$ obtained from the comparison between direct system testing and testing with Matlab.
\end{abstract}

This work is licensed under a Creative Commons Attribution-Share Alike 4.0

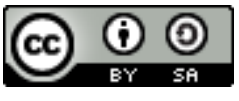

\section{Sitasi Dokumen ini:}

A. B. Setiawan and R. D. Puriyanto, "Pengatur Intensitas Cahaya Ruangan dengan Fuzzy Logic Menggunakan PLC," Buletin Ilmiah Sarjana Teknik Elektro, vol. 1, no. 3, pp. 100--107, 2019. DOI: $\underline{10.12928 / \text { biste.v1i3.1033 }}$ 


\section{PENDAHULUAN}

Perkembangan teknologi tidak hanya untuk kemajuan ilmu pengetahuan, namun juga untuk membantu kebutuhan manusia, Manusia selalu menciptakan teknologi baru yang diharapkan dapat membantu pekerjaan manusia. Dengan kecanggihan teknologi dan serba otomatis manusia dapat lebih menghemat waktu dan mengakibatkan pemborosan biaya [1], banyak yang tidak sadar perkembangan teknologi juga membutuhkan energi yang tidak sedikit untuk dapat bekerja. Penghematan energi menjadi isu hangat yang diperbincangkan, energi yang banyak digunakan dalam keseharian adalah energi untuk penerangan [2].

Manusia memanfaatkan lampu untuk membantu penglihatan apabila dirasa pencahayaan kurang terang pada lingkungan yang sedikit menerima cahaya matahari dari luar. Dalam rangka usaha konservasi energi dan kenyamanan bangunan dan gedung, ada tata cara perancangan sistem pencahayaan alami pada bangunan gedung. Untuk menciptakan rumah hemat energi dapat dimulai dari hal yang sering digunakan di dalam rumah yaitu lampu [2]. Pada umumnya pencahayaan (lampu) mengonsumsi 25\% - 30\% dari total energi listrik untuk sebuah gedung. Faktanya, penggunaan lampu pada sistem pencahayaan di semua sektor masih tidak sepenuhnya efisien karena tidak menggunakan sistem kendali pada pencahayaan tersebut dan disebabkan perilaku juga kesadaran manusia [3].

Pada sistem konvensional yang sudah ada hanya menggunakan prinsip menyalakan dan mematikan lampu. Sistem konvensional masih memiliki kekurangan yaitu dalam hal efektivitas, karena sistem tidak menghiraukan pengaruh dan kontribusi dari pencahayaan dari luar yaitu pencahayaan matahari [4]. Untuk mengatasi permasalahan tersebut dibuatlah sistem pengendalian cahaya lampu penerangan secara otomatis, pengendalian secara otomatis dapat dilakukan dengan berbagai jenis mikrokontroller ataupun PLC. Namun pada penelitian ini akan digunakan jenis PLC Omron sebagai pengendali, karena PLC dapat dengan mudah diprogram sesuai dengan kebutuhan aplikasi. Sehingga dibuatlah prototipe untuk menggambarkan proses pengendalian intensitas cahaya lampu pada ruangan yang memanfaatkan sensor cahaya berjenis Light Dependent Resistance (LDR). Dengan menggunakan metode fuzzy sebagai cara pengambilan keputusan dari sistem, karena fuzzy logic dapat mengatasi permasalahan pada pengontrolan non-linear dan adaptif serta menggunakan pendekatan berdasarkan sifat dan perasaan manusia [5].

\section{METODE PENELITIAN}

\subsection{Metode Fuzzy Logic}

\subsubsection{Pengertian}

Logika Fuzzy merupakan metode yang dapat digunakan untuk mengatasi masalah yang mempunyai banyak jawaban dan digunakan untuk menjelaskan ketidak jelasan [6]. Menurut Prof. Lofti Zadeh pengembang fuzzy logic, bahwa logika benar dan salah dalam logika konvensional tidak dapat mengatasi masalah gradasi yang tidak terhingga. Tidak seperti logika Boolean, logika fuzzy memiliki nilai yang kontinu [7].

\subsubsection{Metode Sugeno}

Metode Sugeno diperkenalkan oleh Takagi Sugeno Kang pada tahun 1985 [7]. Metode Sugeno merupakan metode inferensi fuzzy yang mempresentasikan aturan dalam bentuk IF-THEN, dengan hasil yang dikeluarkan sistem (konsekuen) sudah bukan berupa himpunan fuzzy, melainkan konstanta atau persamaan linear. Untuk mendapatkan fungsi keanggotaan pada penelitian ini digunakan variabel cahaya dengan bentuk gabungan kurva segitiga, kurva linear turun dan kurva linear naik seperti Gambar 1 dan untuk dapat mengetahui derajat keanggotaan dari himpunan, dapat menggunakan (1), (2) dan (3).

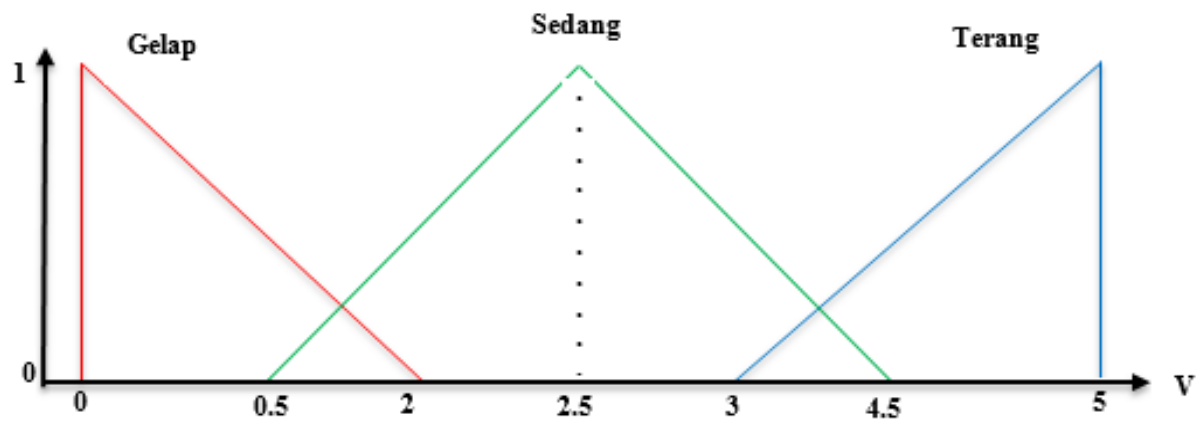

Gambar 1. Kurva himpunan masukan sensor luar dan dalam 


$$
\begin{gathered}
\mu[\text { Gelap }]=\left\{\begin{aligned}
\frac{2-x}{2-0} ; & 0 \leq x \leq 2 \\
0 ; & x \geq 2
\end{aligned}\right. \\
\mu[\text { Sedang }]=\left\{\begin{array}{rc}
0 ; \quad x \leq 0.5 \text { atau } x \geq 4,5 \\
\frac{x-0,5}{2,5-0,5} ; & 0.5 \leq x \leq 2,5 \\
\frac{4,5-x}{4,5-2,5} ; & 2.5 \leq x \leq 4,5
\end{array}\right. \\
\mu[\text { Terang }]=\left\{\begin{aligned}
0 ; & x \leq a \\
\frac{x-3}{5-3} ; & 3 \leq x \leq 5 \\
1 ; & x \geq 5
\end{aligned}\right.
\end{gathered}
$$

Terdapat dua jenis derajat keanggotaan yang dimiliki metode Sugeno yaitu orde 0 dan orde 1, pada penelitian ini digunakan orde 0 , karena hasil persamaan sudah menjadi nilai konstanta. Orde 0 , yang dipresentasikan seperti berikut [8]:

\section{IF (x1 is a1) And (x2 is a2) And (xn is an) THEN $\mathrm{z}=\mathrm{k}$}

Sehingga apabila diimplementasikan ke dalam keadaan yang digunakan menjadi sebuah kalimat yang menyatakan rules pada penelitian ini adalah sebagai berikut:

R1: If (Luar is Gelap) And (Dalam is Gelap) Then (Output is Terang)

R2: If (Luar is Gelap) And (Dalam is Sedang) Then (Output is Terang)

R3: If (Luar is Gelap) And (Dalam is Terang) Then (Output is Padam)

R4: If (Luar is Sedang) And (Dalam is Gelap) Then (Output is Terang)

R5: If (Luar is Sedang) And (Dalam is Sedang) Then (Output is Cukup)

R6: If (Luar is Sedang) And (Dalam is Terang) Then (Output is Padam)

R7: If (Luar is Terang) And (Dalam is Gelap) Then (Output is Terang)

R8: If (Luar is Terang) And (Dalam is Sedang) Then (Output is Padam)

R9: If (Luar is Terang) And (Dalam is Terang) Then (Output is Padam)

Proses defuzifikasi menggunakan metode centroid, dimana untuk mendapatkan nilai crisp nilai yang diperoleh dikalikan dengan bobot dari setiap himpunan. Proses defuzifikasi menggunakan persamaan berikut,

$$
z=\frac{\sum \mu i z i}{\sum \mu i}
$$

Hasil persamaan defuzzyfikasi dengan nilai yang didapat dipresentasikan menjadi sebuah keluaran yang berbentuk singleton yaitu fungsi keanggotaan yang memiliki derajat keanggotaan satu dan nol. Gambar 2 merupakan bentuk keluaran dari sistem yang digunakan.

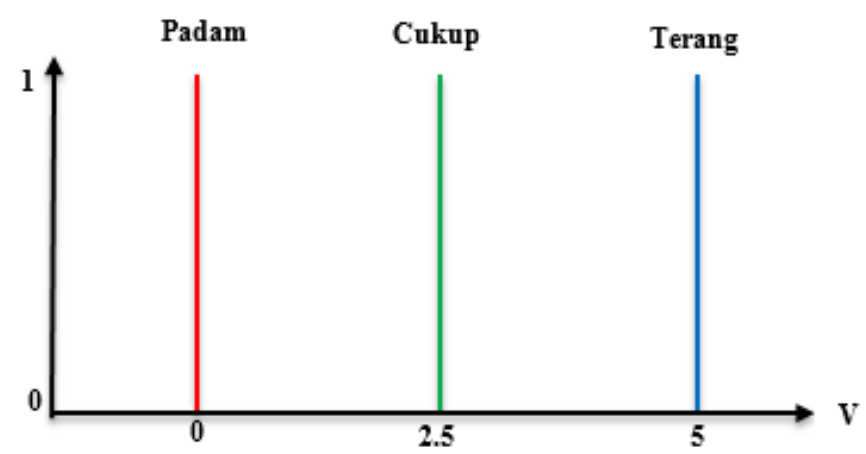

Gambar 2 fungsi derajat keanggotaan keluaran 
Untuk dapat membuktikan hasil pengambilan data menggunakan sistem, dilakukan proses pembanding dengan menggunakan bantuan Matlab. Lalu, dilakukan perhitungan akurasi rata-rata menggunakan persamaan berikut,

$$
\text { Akurasi }=\frac{\text { Nilai Sebenarnya }- \text { Nilai Pengujian }}{\text { Nilai Sebenarnnya }} \times 100 \% \text {. }
$$

\subsection{Desain Sistem}

Penelitian dimulai dari dari perancangan sistem melalui diagram blok yang mengacu pada teori yang digunakan serta datasheet komponen yang diperoleh dari sumber terpercaya. Pada Gambar 3 menggambarkan alur perangkat bekerja yang dimulai dari pembacaan sinyal analog hingga mengaktifkan aktuator.

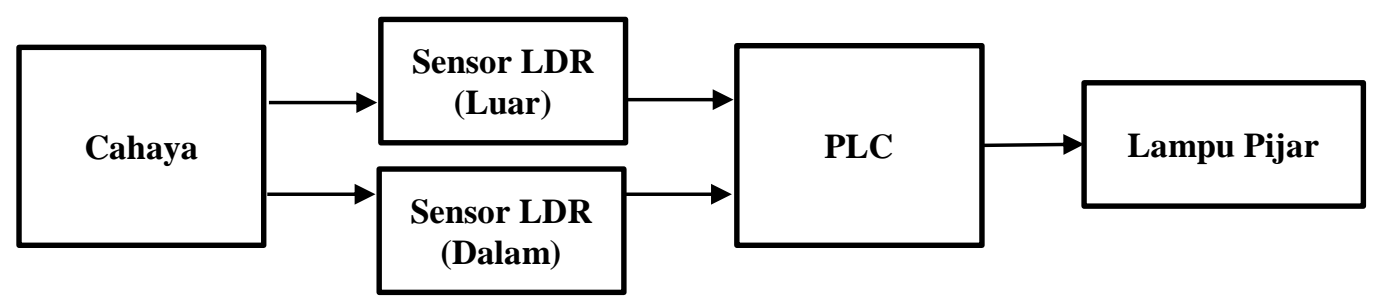

Gambar 3. Diagram blok sistem

Dari Gambar 3 diawali dengan intensitas cahaya yang terbaca oleh sensor LDR, akan mengirimkan sinyal analog ke PLC menggunakan kabel penghubung untuk dilakukan pemrosesan perhitungan menggunakan metode pendekatan fuzzy yang hasil pemrosesan dikirimkan ke lampu sehingga intensitas cahaya lampu menyala sesuai dengan kondisi yang diinginkan

\subsubsection{Pencahayaan Buatan}

Cahaya merupakan satu bagian dari berbagai jenis gelombang elektromagnetik yang terbang ke angkasa. Gelombang tersebut memiliki panjang dan frekuensi tertentu yang nilainya dibedakan dari energi cahaya lainya dalam spektrum elektromagnetiknya. Metode penggunaan pencahayaan berdasarkan SNI 03-0000-2001 dengan penentuan tingkat pencahayaan minimum yang direkomendasikan tercantum dalam Tabel 1.

Tabel 1. Tingkat pencahayaan yang direkomendasikan

\begin{tabular}{ccc}
\hline Fungsi Ruangan & $\begin{array}{c}\text { Tingkat } \\
\text { Pencahayaan (Lux) }\end{array}$ & $\begin{array}{c}\text { Kelompok } \\
\text { Renderisasi Warna }\end{array}$ \\
\hline Rumah Tinggal & & \\
Teras & 60 & 1 atau 2 \\
1 atau 2 \\
Ruang Tamu & $120-250$ & 1 atau 2 \\
Ruang Makan & $120-250$ & 1 atau 2 \\
Kamar Tidur & $120-250$ & atau 2 \\
Dapur & 250 & \\
Perkantoran & & 1 atau 2 \\
Ruang Kelas & & 1 atau 2 \\
Perpustakaan & 250 & 1 \\
Laboratorium & 300 & \\
\hline
\end{tabular}

\subsubsection{Sensor Cahaya}

Sensor cahaya dengan jenis Light Dependent Resistor (LDR) merupakan jenis resistor yang dapat berubah nilai hambatannya karena pengaruh cahaya, jika cahaya gelap nilai tahanan akan semakin besar dan jika cahaya terang nilai hambatan berubah menjadi semakin kecil, nilai resistansi LDR berubah seiring dengan perubahan intensitas cahaya yang diterimanya dengan kata lain nilai hambatannya berbanding lurus dengan cahaya yang diterima. Sensor LDR terbuat dari bahan semikonduktor sehingga energi dari cahaya yang diterima sensor 
menyebabkan muatan yang dilepas atau arus listrik meningkat atau nilai resistansinya telah mengalami penurunan [9]. Sensor LDR dapat disimbolkan seperti Gambar 4.

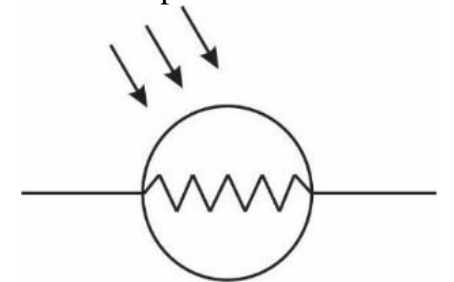

Gambar 4. Lambang Sensor LDR

Sensor LDR memiliki rumus seperti persamaan sebagai berikut,

$$
I=\frac{\mathrm{V}}{\mathrm{R}}
$$

dengan I adalah arus, $\mathrm{R}$ adalah hambatan dan $\mathrm{V}$ adalah tegangan. Semakin besar nilai hambatan, semakin kecil nilai arus, sementara semakin kecil nilai hambatan, semakin besar nilai arusnya.

\subsubsection{Programmable Logic Controller}

National Electrical Manufacturers Association mendefinisikan sebagai perangkat elektronika yang menggunakan memori yang dapat dikendalikan sebagai penyimpan instruksi juga menjalankan beberapa fungsi khusus, seperti logika, sequence (rutin), timing (pewaktuan), counting (penghitungan) dan operasi aritmatika untuk mengendalikan proses yang dilakukan mesin. Gambar 5 menunjukkan unit PLC Omron CP1E NA DRA yang digunakan dalam penelitian ini.

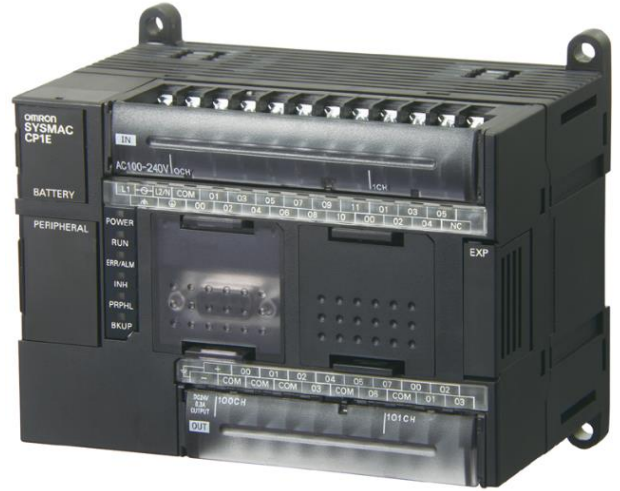

Gambar 5. PLC Omron CP1E NA DR-A

PLC digunakan sebagai unit pemrosesan data masukan dan menghasilkan keluaran sesuai dengan yang diharapkan. PLC Omron CP1E NA DR-A dilengkapi dengan fitur utama yang dapat digunakan, adapun fitur tersebut adalah[10]:

1. Memiliki analog I/O, dua masukan analog dan satu keluaran analog;

2. Terdapat Mounting Serial Option Boards, Ethernet Option Board dan Analog Options Board;

3. Hubungan dengan komputer dapat menggunakan Unit Serial Bus (USB);

4. Terminal ekspansi agar terminal I/O analog dan digital dapat ditambah;

5. Dilengkapi dengan high speed counter yang lengkap.

\subsection{Desain Perangkat Lunak}

Sistem diawali dengan sensor LDR membaca nilai cahaya yang diterima, nilai yang dibaca oleh sensor kemudian diproses untuk menjadi sebuah himpunan bernama himpunan cahaya, pada penelitian ini menggunakan dua buah variabel cahaya yang sama, yang masing-masing variabel memiliki tiga himpunan, yaitu gelap, sedang dan terang. Nilai yang terbaca oleh sensor akan masuk ke salah satu himpunan yang selanjutnya akan dilakukan proses inferensi, yaitu proses pengambilan keputusan. Keputusan dari inferensi akan dimasukkan ke proses defuzifikasi dimana nilai yang masuk akan diubah menjadi nilai crisp. Gambar 6 merupakan flowchart dari perangkat lunak pada penelitian ini. 

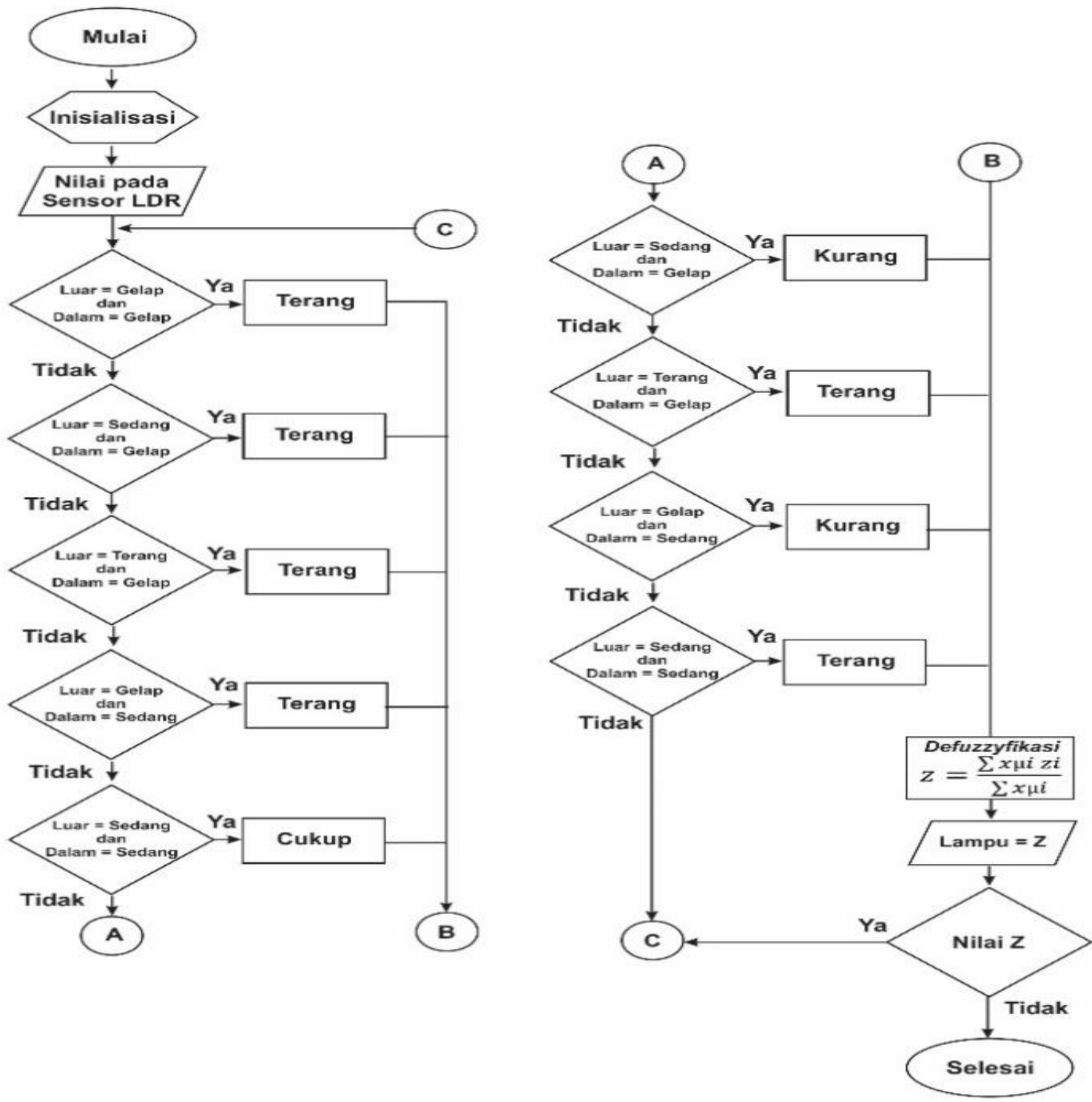

Gambar 6 Diagram alir perangkat lunak

\section{HASIL DAN PEMBAHASAN}

\subsection{Pengujian Sensor LDR}

Pengujian dilakukan dengan cara memberikan cahaya kepada kedua sensor dengan jarak antara sumber cahaya dan modul sensor bervariasi. Dari hasil pembacaan sensor lalu di bandingkan dengan nilai yang terbaca pada lux meter. Tabel 2 merupakan hasil dari pengujian sensor LDR.

Tabel 2 Hasil pengujian dari sensor LDR

\begin{tabular}{ccccc}
\hline \multirow{2}{*}{ No } & $\begin{array}{c}\text { Jarak Cahaya ke } \\
\text { Sensor }(\mathbf{C m})\end{array}$ & \multicolumn{2}{c}{ Tegangan Keluaran Sensor LDR $(\mathbf{V})$} & \multirow{2}{*}{$\begin{array}{c}\text { Lumen } \\
\text { Sensor Luar }\end{array}$} \\
\hline 1 & 55 & 1,45 & Sensor Dalam & $($ Lx $)$ \\
2 & 50 & 1,3 & 1,01 & 39 \\
3 & 45 & 1,10 & 0,77 & 63 \\
4 & 40 & 1,10 & 0,64 & 73 \\
5 & 35 & 0,95 & 0,66 & 90 \\
6 & 30 & 0,85 & 0,5 & 109 \\
7 & 25 & 0,78 & 0,54 & 138 \\
8 & 20 & 0,5 & 0,5 & 185 \\
9 & 15 & 0,38 & 0,36 & 281 \\
10 & 10 & 0,28 & 0,28 & 442 \\
\hline
\end{tabular}


Pengujian sensor LDR dilakukan di dalam ruangan dengan cahaya lampu ruangan sebesar 23 lx. Dari Tabel 2 yang diperoleh menunjukkan bahwa semakin dekat cahaya kepada sensor maka tegangan yang dihasilkan sensor semakin kecil karena semakin besar cahaya yang diterima maka tahanan yang diberikan pada sensor semakin besar juga. Sedangkan yang terbaca pada lux meter akan semakin besar karena intensitas cahaya yang diterima semakin besar. Dari hasil pengujian pada Tabel 3 menunjukkan bahwa modul sensor yang digunakan sudah sesuai dengan teori yang digunakan pada penelitian ini, bahwa nilai tahanan pada sensor akan semakin besar.

\subsection{Pengujian Sistem}

Setelah melakukan perancangan perangkat keras untuk pengatur intensitas cahaya ruangan didapat hasil berupa prototipe pengatur intensitas cahaya ruangan seperti pada Gambar 7 .

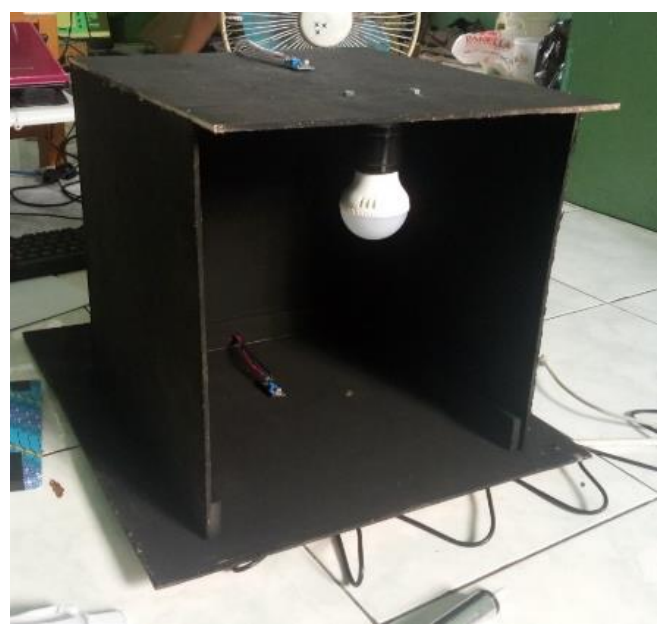

Gambar 7 Purwarupa pengatur intensitas cahaya

Prototipe terdiri dari sebuah kotak yang terbuat dari papan triplek yang digunakan sebagai simulasi dari ruangan, PLC (Programmable Logic Controller) sebagai pengendali dari sistem, dua buah modul sensor LDR (Light Dependent Resistor) yang satu diletakan di dalam kotak digunakan untuk membaca cahaya yang ada didalam kotak, sekaligus menjadi umpan balik dari cahaya lampu, yang satu lagi di letakan di luar kotak yang digunakan untuk membaca cahaya luar dan lampu pijar sebagai komponen yang dikendalikan oleh sistem. Penyusun prototipe pengatur intensitas cahaya ruangan dirangkai agar menjadi sebuah sistem yang terintegritas dengan menghubungkan semua komponen. Pengujian di lakukan di ruangan tertutup dengan kondisi lampu menyala.

Pengujian dilakukan dengan cara memberikan intensitas cahaya yang berbeda-beda pada setiap sensor, yang hasil nilia pembacaannya digunakan sebagai masukan sistem dan dilakukan perhitungan secara sistematis menggunakan program yang telah dibuat di PLC, sehingga menghasilkan nilai tegangan yang digunakan untuk mengatur intensitas cahaya pada prototipe ruangan yang telah dibuat. Tabel 3 merupakan hasil pengujian sistem yang dibandingkan dengan hasil perhitungan menggunakan Matlab.

Tabel 3 Hasil pengujian sistem

\begin{tabular}{cccccc}
\hline \multirow{2}{*}{ Ke-- } & \multicolumn{2}{c}{ Masukan Cahaya } & \multicolumn{3}{c}{ Hasil } \\
\cline { 2 - 6 } & Luar $(\mathbf{V})$ & Dalam $(\mathbf{V})$ & Sistem $(\mathbf{V})$ & Matlab (V) & Akurasi (\%) \\
\hline 1 & 0,69 & 0,26 & 5 & 5 & 100 \\
\hline 2 & 0,67 & 1,06 & 4,75 & 4,77 & 99,58 \\
\hline 3 & 3,22 & 0,25 & 4,24 & 4,27 & 99,29 \\
\hline 4 & 3,33 & 0,28 & 3,87 & 3,9 & 99,23 \\
\hline 5 & 1,58 & 3,72 & 2,62 & 2,63 & 98,61 \\
\hline 6 & 1,56 & 3,97 & 2,38 & 2,41 & 98,75 \\
\hline 7 & 1,80 & 3,81 & 1,94 & 1,96 & 98,97 \\
\hline 8 & 2,81 & 3,56 & 1,55 & 1,57 & 98,72 \\
\hline 9 & 2,78 & 4,00 & 0,83 & 0,833 & 99,63 \\
\hline 10 & 4,08 & 3,52 & 0,44 & 0,44 & 100 \\
\hline \multicolumn{5}{c}{ Akurasi Rata-Rata } \\
\hline
\end{tabular}

Dari Tabel 3 didapat akurasi sistem yang telah dibandingkan dengan perhitungan Matlab yang menghasilkan tingkat akurasi sebesar 99, 38\%. 


\section{KESIMPULAN}

Setelah dilakukan pengujian dan pengamatan pada penelitian ini, peneliti mendapatkan kesimpulan bahwa sistem yang dibuat telah dapat melakukan kendali menggunakan fuzzy logic, keluaran sistem berupa kondisi lampu yang diwakilkan oleh besar kecil tegangan yang dihasilkan oleh PLC dan sistem yang telah dibuat dapat menghasilkan tingkat akurasi 99,38\%, didapat dari perbandingan dengan menggunakan hasil perhitungan Matlab.

\section{UCAPAN TERIMA KASIH}

Pada kesempatan ini, penulis sampaikan terima kasih kepada editor dan reviewer atas segala bentuk saran, masukan dan telah membantu proses penerbitan naskah. Penulis juga sampaikan terima kasih kepada pihakpihak yang telah mendukung penelitian dan memberikan bantuan moral dan material.

\section{REFERENSI}

[1] E. Desyantoro, A. F. Rochim, and K. T. Martono, "Sistem Pengendalian Peralatan Elektronika dalam Rumah secara Otomatis Menggunakan Sensor PIR, Sensor LM35 dan Sensor LDR,” J. Teknol. dan Sist. Komput., vol. 3, pp. 405-411, 2015. doi: 10.14710/jtsiskom.3.3.2015.405-411

[2] A. M. H. Pardede, Novriyenni, and S. Efendi, "Implementasi Pengendalian Lampu Otomatis Berbasis Arduino Menggunakan Metode Fuzzy Logic,” Techsi, vol. 9, no. 2, 2017. doi: 10.29103/techsi.v9i2.221

[3] G. Otomo and Wildian, "Sistem Kontrol Penyalaan Lampu Ruang Berdasarkan Pendeteksian Ada Tidaknya Orang di Dalam Ruangan,” J. Fis. Unand, vol. 2, no. 4, pp. 225-261, 2013. Online

[4] M. D. Putro and F. D. Kambey, "Sistem Pengatur Pencahayaan Ruangan Berbasis Android Pada Rumah Pintar," J. Nas. Tek. Elektro, vol. 5, no. 3, 2016. doi: 10.25077/jnte.v5n3.294.2016

[5] M. Nadhif and Suryono, "Aplikasi Fuzzy Logic untuk Pengendali Motor DC Berbasis Mikrokontroler ATMega8535 dengan Sensor Photodioda," J. Tek. Elektro, vol. 7, pp. 81-85, 2015. doi: 10.15294/jte.v7i2.8594

[6] G. Turesna, Zulkarnain, and Hermawan, "Pengendali Intensitas Lampu Ruangan Berbasis Arduino UNO Menggunakan Metode Fuzzy Logic," J. Otomasi Kontrol Instrumentasi, vol. 7, no. 2, pp. 73-88, 2015. doi: 10.5614\%2Fjoki.2015.7.2.2

[7] I. Widya and Nazori, "Prototipe Model Prediksi Peluang Kejadian Hujan Menggunakan Metode Fuzzy Logic Tipe Mamdani dan Sugeno," J. TICom, vol. 1, no. 1, p. 60, 2012. Online

[8] V. Kurniati, D. Triyanto, and T. Rismawan, "Penerapan Logika Fuzzy dalam Sistem Prakiraan Cuaca Berbasis Mikrokontroller," J. Coding, Sist. Komput. Untan, vol. 05, no. 2, pp. 119-128, 2017. Online

[9] S. Supatmi, "Pengaruh Sensor LDR Terhadap Pengontrolan Lampu," Maj. Ilm. UNIKOM, vol. 8, no. 2, p. 176, 2016. Online

[10] A. Junaidi and W. S. Aji, "Sistem Pengontrol Suhu Ruangan dengan Algoritma PID Menggunakan PLC Omron CP1e-NA20DR-A," J. Ilm. Tek. Elektro Komput. dan Inform., vol. 3, no. 2, p. 47, 2017. doi: $\underline{10.26555 / j i t e k i . v 3 i 2.7069}$

\section{BIOGRAFI PENULIS}

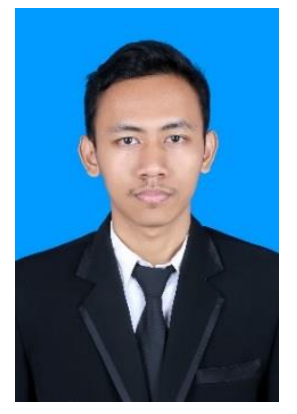

\section{Arif Budi Setiawan}

Penulis pertama adalah mahasiswa S1 program studi Teknik Elektro di Universitas Ahmad Dahlan Yogyakarta yang telah menyelesaikan pendidikan sarjana pada program studi tersebut.

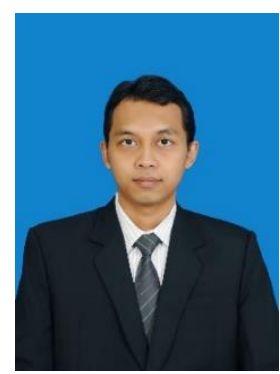

\section{Riky Dwi Puriyanto S.T., M. Eng}

Penulis kedua adalah dosen di Program Studi Teknik Elektro Universitas Ahmad Dahlan Yogyakarta. Penulis kedua memiliki latar belakang pendidikan S1 Teknik Elektro di Universitas Gajah Mada Yogyakarta dan pendidikan S2 di Universitas Gajah Mada Yogyakarta dengan bidang Renewable Energy and Signal Processing. 